\title{
Waterpipe device cleaning practices and disposal of waste associated with waterpipe tobacco smoking in homes in the USA
}

\author{
Nada OF Kassem (10, Noura O Kassem, Sandy Liles 주 , Erin Reilly, Flora Kas-Petrus, \\ Alexander Ivan B Posis, Melbourne F Hovell
}

San Diego State University Research Foundation, San Diego, California, USA

Correspondence to Dr Nada OF Kassem, San Diego State University Research Foundation, San Diego, CA 92123, USA:

nkassem@cbeachsdsu.org

Received 22 January 2019 Revised 23 April 2019

Accepted 1 May 2019 Published Online First 20 July 2019

\begin{abstract}
Objectives To quantify postsmoking waterpipe tobacco (WPT) waste and describe postsmoking waterpipe (WP) device cleaning practices and disposal of associated waste in home settings.

Methods We analysed data from a US convenience sample of 50 exclusive WPT smokers, mean age 25.3 years. Data were collected at a home visit during which participants smoked one WPT head and completed a self-administered questionnaire on WP cleaning practices and disposal of waste associated with WPT use. Research assistants provided and prepared a WP for participants by weighing and loading $10 \mathrm{~g}$ of WPT in the WP head and placing $470 \mathrm{~mL}$ of water in the WP bowl. At the completion of the smoking session, research assistants measured the remaining WPT and water. Descriptive analyses were performed.

Results Of the $10 \mathrm{~g}$ of fresh WPT used for each smoking session, $70.1 \%$ (mean=7.01 g) was discarded postsmoking as waste; for each $470 \mathrm{~mL}$ of water used in the WP bowl, $94.3 \%$ (mean=443 mL) was discarded. WP device cleaning practices ranged from never cleaning the device to cleaning it after each smoking session. Respondents reported discarding smoked WPT residue in the trash $(81.6 \%)$ or the kitchen sink (14.3\%) and discarding postsmoking charcoal in the trash (57.6\%), the kitchen sink (27.3\%) or backyard soil (9.1\%). Respondents reported discarding smoked WP water in the kitchen sink (76.5\%), bathroom sink (14.7\%), toilet (2.9\%) and backyard soil (5.9\%).
\end{abstract}

Conclusions Interventions and regulations are needed to inform proper WP device cleaning practices and disposal of waste associated with WPT use.

Trial registration number NCT03253653.

\section{INTRODUCTION}

Global efforts to mitigate the adverse impact of postconsumption tobacco waste on the environment are on the rise, ${ }^{1-9}$ prompted by concern over the 1.69 billion $\mathrm{lbs}$ (720 million $\mathrm{kg}$ ) of cigarette butts that end up as toxic waste annually. ${ }^{310}$ While regulatory efforts to reduce the environmental effects of tobacco product waste have been focused on cigarettes, ${ }^{1-10}$ similar attention is warranted for other tobacco products. Waterpipe tobacco (WPT) use is currently considered a global health problem, particularly among youth and young adults in several eastern Mediterranean, eastern European and western countries, including the USA. ${ }^{11-20}$ Prevalence estimates among adults in 68 countries are highest in the eastern Mediterranean, and among youth are about equal in the eastern Mediterranean and European regions. ${ }^{12}$ In the USA, a nationally representative sample (2013-2014) showed that $13 \%$ of $15-17$-year olds have ever used WPT, and $2.9 \%$ have used WPT in the past 30 days; among 18-24-year olds, 44.4\% have ever used WPT and $18.2 \%$ are current WPT users. ${ }^{20}$

WPT is smoked using a waterpipe (WP) device (also known as hookah, argileh, nargile, shisha or galyan) in which smoke passes through water. The WP consists of a head (bowl), a stem (body) which is a vertical tube that passes into a partially filled bowl (water jar) and a flexible hose with a mouthpiece. Burning charcoal heats the WPT, which produces the smoke that the user inhales via the hose.

The majority of WPT smokers use flavoured WPT. ${ }^{11}{ }^{21-27}$ Flavoured WPT, known as 'Moassel' (also known as Mu'assel or Maassel), is a mixture of about 30\% tobacco and natural/artificial flavourings, sweeteners (eg, molasses, honey, sugars) and humectants (eg, propylene glycol). ${ }^{23-28}$ WPT smoking has been associated with increased risk for lung and oral cancers, coronary heart and pulmonary diseases. ${ }^{29-31}$ The growing popularity of WPT smoking not only increases the number of smokers exposed to health risks ${ }^{11-20}$ but also may lead to increases in environmental contamination due to the disposal of postconsumption WPT waste. Postsmoking WPT waste includes the smoked WPT residue (remnants of the heated WPT found in the WP head at the end of a smoking session), aluminium foil (that covers the WPT by wrapping it around the WP head to avoid burning the WPT), burnt charcoal (charcoal remnants after burning) and smoked WP water (water in the WP bowl through which WPT and charcoal smoke bubble during smoking); other WPT waste includes the packaging of the WPT.

Unlike cigarettes, postsmoking WPT toxic chemicals may be disposed into the environment via waste generated in the various components of the WP device. Toxic chemicals found in fresh (unsmoked) WPT have been found in the smoked WPT residue and to some degree in the smoked WP water. ${ }^{25} 32-36$ For example, $40 \% \pm 18 \%$ of metal content in fresh WPT remained at the end of a smoking session in the smoked WPT residue, and 3\% $01 \%$ remained as dissolved/suspended metal in the smoked WP water. ${ }^{32}$ Eighteen toxic elements have been detected in samples of smoked WP water, including arsenic, lead, cadmium, mercury and uranium, which are environmental contaminants. ${ }^{33}$ Other harmful 
compounds detected in smoked WP water include carcinogenic furanic compounds, toxic carbonyls (eg, formaldehyde, acetaldehyde and acrolein), phenolic compounds, primary aromatic amines and volatile organic pollutants (eg, toluene). ${ }^{25}{ }^{34-37}$ Therefore, postsmoking WPT waste should be characterised, quantified and controlled to limit its level of accumulation in the environment.

Homes represent a social setting where WPT smoking frequently takes place. ${ }^{38-43}$ We previously found that WPT smokers smoke at home to relax comfortably, eat and drink while smoking and save money by not going to hookah lounges/ cafés. ${ }^{39}$

To our knowledge, this is the first study to quantify postsmoking WPT waste and describe post-smoking WP device cleaning practices and disposal of waste associated with WPT use in natural home settings. The environmental, consumer and regulatory implications of our findings are discussed.

\section{METHODS}

\section{Participant recruitment, screening and consent}

Between December 2017 and September 2018, we recruited a convenience sample of 50 WPT smokers (25 men, 25 women) from San Diego County, California, USA via posting flyers on bulletin boards at community colleges, universities and cafes, sharing electronic flyers on social media such as Instagram, Facebook, Snapchat, Reddit and Twitter and encouraging already recruited participants to enlist others by word of mouth. Trained research assistants (RAs) qualified participants by phone via a screening form based on the inclusion/exclusion criteria, invited them to an office visit during which we explained study activities, obtained signed informed consent forms and scheduled a home visit.

Inclusion criteria were as follows: exclusive WPT smoker; aged 21 years or older; who smoked WPT exclusively; smoked at least one WPT head per month; smoked at least one WPT head per smoking session and smoked WPT at home. Exclusion criteria were: major physical/psychiatric illnesses judged by RAs to interfere with providing informed consent or completing an interview; history of chronic health problems (eg, asthma, hypertension); regular use of prescription medication (other than vitamins or birth control) or pregnancy.

A total of 101 respondents were screened by phone; 54 were eligible and were enrolled in the study. Four participants withdrew from the study before the home visit (due to travel or change of mind).

\section{Study design}

Data were collected during a single session for each of 50 WPT smoker participants who smoked one WPT head (not shared with other smokers). RAs collected postsmoking WPT waste. Participants completed a self-administered questionnaire that had structured and open-ended questions about demographics, WPT smoking behaviour, WP cleaning practices and disposal of postsmoking WPT waste and received \$75 in cash.

\section{WPT smoking session and materials}

The RAs provided the smokers with a medium-sized WP (height $=22$ inches $(55.8 \mathrm{~cm})$; Khalil Mamoon Safari brand, Egypt) and a disposable plastic hose (length $=50$ inches $(125$ $\mathrm{cm}$ ); Fancy Hose, Zebra Smoke brand, Amazon.com). The RAs set up the WP following a standardised protocol. Briefly, the RAs placed a standardised volume $(470 \mathrm{~mL})$ of room temperature commercial drinking water (Nestlé Pure Life Purified
Bottled Water brand, USA) in the WP bowl. The metal stem was covered with inch $(2.5 \mathrm{~cm})$ of water. The RAs weighed (using an analytical balance) and loaded one head of flavoured WPT (10 g; Exotic Double Apple flavour, Starbuzz brand, USA) in the ceramic head and covered it with a manufacturer preperforated sheet of aluminium foil (Zebra Smoke brand, Amazon.com). The RAs lit a single quick-light charcoal $(40 \mathrm{~mm}$; Three Kings brand, Holland) and placed it on the foil-covered WP head (no additional charcoal was added). Participants ended smoking when desired; however, they were instructed that the WP would be available for $45 \mathrm{~min}$.

At the conclusion of the home visit, the RAs returned the WP device and WPT use waste (in sealed Ziploc bags) to our centre; waste was disposed of in our laboratory biohazard trash (disposable hose, smoked WPT residue, aluminium foil, gloves). With permission from the WPT smoker, the burnt charcoal ash was cooled in our study water bucket and was disposed of in the participant's kitchen sink along with the smoked WP water, after which the sink was cleaned with running water.

\section{Measures}

\section{Demographics and WPT smoking behaviors}

We asked about age, gender, education, race/ethnicity, age at WPT smoking initiation and WP sharing behaviours.

\section{Quantification of postsmoking WPT waste}

At the conclusion of the WPT smoking session, the RAs weighed the smoked WPT residue using an analytical balance, measured the volume of water remaining in the WP bowl and recorded session length from first to last puff.

\section{WP device cleaning practices and disposal of postsmoking WPT waste}

We asked about WP hose and stem cleaning practices postsmoking WPT and location of usual disposal of postsmoking WPT residue, burnt charcoal and smoked WP water in home settings.

\section{Analyses}

Data were double entered and analysed in Excel. Descriptive analyses included arithmetic means and SD, medians and 5th and 95th percentiles and minimum and maximum values. For openended questions, participants' responses were manually grouped into themes independently by two coders. Coders discussed the discrepancies and made modifications.

\section{RESULTS}

\section{Demographics and WPT use}

Participants (mean age, 25.3 years) were $50 \%$ men and identified as white (22\%), Hispanic (32\%), black (10\%), Asian (4\%), Middle Eastern/Arab, Chaldean, Persian or Kurdish (26\%) or multiethnic (6\%) (table 1). The majority of participants had either a college degree $(50 \%)$ or some college (36\%) (table 1). About two-thirds (60\%) resided in homes and one-third (38\%) resided in apartments (table 1). Participants were weekly $(62 \%)$ or monthly (38\%) WPT smokers (table 1). Participants reported smoking an average of one WPT head on the day they smoked (table 1 ).

\section{Quantification of WPT use waste}

WPT smokers smoked for an average of one-half hour (mean $=33.1 \mathrm{~min}$ ) during the observed WPT smoking session at home, using $10 \mathrm{~g}$ of WPT, one charcoal $(40 \mathrm{~mm})$ and 
Table 1 Demographics, WPT use and disposal of WPT use waste by WPT smokers in natural home settings $(\mathrm{N}=50)$

\begin{tabular}{|c|c|}
\hline & $\mathrm{n}(\%)$ \\
\hline \multicolumn{2}{|l|}{ Age (years) } \\
\hline Mean $( \pm S D)$ & $25.3( \pm 3.13)$ \\
\hline Median (minimum-maximum) & $25(21-35)$ \\
\hline \multicolumn{2}{|l|}{ Gender } \\
\hline Male & $25(50)$ \\
\hline Female & $25(50)$ \\
\hline \multicolumn{2}{|l|}{ Highest level of education completed } \\
\hline High school & $7(14)$ \\
\hline College, no degree & $18(36)$ \\
\hline College degree & $25(50)$ \\
\hline \multicolumn{2}{|l|}{ Race/Ethnicity } \\
\hline White, Caucasian, European & $11(22)$ \\
\hline Mexican, Hispanic or Latino & $16(32)$ \\
\hline Black or African American & $5(10)$ \\
\hline Asian & $2(4)$ \\
\hline Middle Eastern/Arab, Chaldean, Persian, Kurdish & $13(26)$ \\
\hline Multiethnic & $3(6)$ \\
\hline \multicolumn{2}{|l|}{ Type of natural home setting } \\
\hline Home & $30(60)$ \\
\hline Apartment & $19(38)$ \\
\hline Other: townhouse & $1(2)$ \\
\hline \multicolumn{2}{|l|}{ Do you currently smoke WPT daily, weekly or monthly? } \\
\hline Weekly at least once each week but less than daily & $31(62)$ \\
\hline Monthly at least once a month but less than weekly & $19(38)$ \\
\hline \multicolumn{2}{|c|}{$\begin{array}{l}\text { How many WPT heads do you usually smoke on the day you } \\
\text { smoke? }\end{array}$} \\
\hline Mean ( \pm SD) & $1.3( \pm 0.56)$ \\
\hline Median (minimum-maximum) & $1(0.5-3)$ \\
\hline \multicolumn{2}{|l|}{ What type of WPT do you currently smoke? } \\
\hline Only flavoured & $46(92)$ \\
\hline Only unflavoured & $0(0)$ \\
\hline Flavoured and unflavored equally & $0(0)$ \\
\hline Flavoured more than unflavored & $3(6)$ \\
\hline Unflavored more than flavoured & $1(2)$ \\
\hline \multicolumn{2}{|l|}{ How often do you share a WP with someone you know? } \\
\hline Almost always/often & $44(88)$ \\
\hline Rarely/never & $6(12)$ \\
\hline \multicolumn{2}{|c|}{ How often do you share a WP with someone you just met? } \\
\hline Almost always/often & $10(20)$ \\
\hline Rarely/never & $40(80)$ \\
\hline \multicolumn{2}{|c|}{$\begin{array}{l}\text { After smoking WPT at home, where do you usually discard } \\
\text { the remaining smoked WPT residue? }\end{array}$} \\
\hline In the trash & $40(81.6)$ \\
\hline Kitchen sink & $7(14.3)$ \\
\hline Bathroom sink & $0(0)$ \\
\hline Toilet & $0(0)$ \\
\hline In the backyard soil & $1(2)$ \\
\hline In the plant pot indoors & $1(2)$ \\
\hline \multicolumn{2}{|c|}{$\begin{array}{l}\text { After smoking WPT at home, where do you usually discard } \\
\text { the remaining burnt charcoal? }\end{array}$} \\
\hline In the trash & $27(55.1)$ \\
\hline Kitchen sink & $14(28.6)$ \\
\hline Bathroom sink & $0(0)$ \\
\hline Toilet & $2(4.1)$ \\
\hline In the backyard soil & $5(10.2)$ \\
\hline In the plant pot indoors & $1(2)$ \\
\hline Smoked WP water & \\
\hline
\end{tabular}

Continued

\section{Table 1 Continued}

$\mathrm{n}(\%)$

After smoking how many WPT heads at home do you
replace the water in the WP bowl with fresh water?

Mean $( \pm S D)$

$2.1( \pm 1.36)$

Median (minimum-maximum)

$2(0-7)$

When you decide to replace the smoked WP water with fresh water, where do you usually discard the water?

\begin{tabular}{ll} 
Kitchen sink & $36(72)$ \\
\hline Bathroom sink & $7(13.7)$ \\
Toilet & $2(3.9)$ \\
In the backyard soil & $4(7.8)$ \\
In the plant pot indoors & $0(0)$ \\
Other places: street storm drain & $1(2)$
\end{tabular}

After smoking WPT at home, when you pour the smoked WP water, do you usually smell anything?

$\begin{array}{ll}\text { Yes } & 24(52.2) \\ \text { No } & 22(47.8)\end{array}$

After discarding the smoked WP water, do you usually see any material left in the WP bowl?

$\begin{array}{ll}\text { Yes } & 20(42.6) \\ \text { No } & 27(57.5)\end{array}$

WP hose

Have you ever cleaned the WP hose that you use at home?

$$
\begin{array}{ll}
\text { Yes } & 33(68.7) \\
\text { No } & 15(31.3)
\end{array}
$$

If Yes, do you clean the WP hose at home after every WPT smoking session?

$$
\begin{array}{ll}
\text { Yes } & 11(35.5) \\
\text { No } & 20(64.5)
\end{array}
$$

Where do you usually clean your WP hose that you use at home?

\begin{tabular}{ll} 
Kitchen sink & $26(78.8)$ \\
\hline Bathroom sink & $4(12.1)$ \\
\hline In the backyard & $3(9.1)$
\end{tabular}

How long have you been using the WP hose that you currently smoke at home (months)?

$\begin{array}{ll}\text { Mean }( \pm \mathrm{SD}) & 7.5( \pm 6.94) \\ \text { Median (minimum-maximum) } & 6(1-24)\end{array}$

Have you ever shared the WP hose that you use when you smoke WPT at home?

$$
\begin{array}{ll}
\text { Yes } & 39(84.8) \\
\text { No } & 7(15.2)
\end{array}
$$

WP stem

Have you ever cleaned the WP stem that you use at home?

$\begin{array}{ll}\text { Yes } & 34(72.3) \\ \text { No } & 13(27.7)\end{array}$

If Yes, do you clean the WP stem that you use at home after every WPT smoking session?

$$
\begin{array}{ll}
\text { Yes } & 16(50) \\
\text { No } & 16(50)
\end{array}
$$

Where do you usually clean your WP stem that you use at home?

\begin{tabular}{ll} 
Kitchen sink & $30(85.6)$ \\
\hline Bathroom sink & $3(8.6)$ \\
\hline In the backyard & $1(2.9)$ \\
\hline Other places: shower & $1(2.9)$
\end{tabular}

How long have you been using the WP stem that you currently use to smoke hookah at home (months)?

$$
\begin{array}{ll}
\text { Mean }( \pm \mathrm{SD}) & 12.9( \pm 19.95) \\
\text { Median (minimum-maximum) } & 6(1-120)
\end{array}
$$

The response item 'other places' was provided in all location of disposal questions; only those with responses are provided in the table. Due to missing values, some variables do not total the sample size 50 .

WP, waterpipe; WPT, waterpipe tobacco. 
Table 2 WPT smoking consumption and waste for one smoking session, using $10 \mathrm{~g}$ of WPT and $470 \mathrm{~mL}$ water in the WP bowl ( $\mathrm{N}=50)$

\begin{tabular}{|c|c|c|c|}
\hline WPT (g) & $\begin{array}{l}\text { WPT loaded } \\
\text { in WP head } \\
\text { presmoking* }\end{array}$ & WPT consumed & $\begin{array}{l}\text { Smoked WPT } \\
\text { residuet }\end{array}$ \\
\hline Mean $( \pm$ SD) & 10 & $2.99( \pm 0.93)$ & $7.01( \pm 0.93)$ \\
\hline $\begin{array}{l}\text { Median (5-95 } \\
\text { percentile) } \\
\text { (Minimum-maximum) }\end{array}$ & & $\begin{array}{l}3.00(1.5-4.7) \\
(0.5-5.2)\end{array}$ & $\begin{array}{l}7.00(5.3-8.5) \\
(4.8-9.5)\end{array}$ \\
\hline WP water (mL) & $\begin{array}{l}\text { Water placed } \\
\text { in WP bowl } \\
\text { presmoking } \ddagger\end{array}$ & WP water loss & $\begin{array}{l}\text { Smoked WP } \\
\text { water§ }\end{array}$ \\
\hline Mean $( \pm$ SD) & 470 & $26.3( \pm 24.50)$ & $443( \pm 24.50)$ \\
\hline $\begin{array}{l}\text { Median (5-95 } \\
\text { percentile) }\end{array}$ & & $20.0(0-70)$ & $450(400-470)$ \\
\hline (Minimum-maximum) & & $(0-165)$ & $(305-470)$ \\
\hline \multicolumn{4}{|c|}{ Length of time smoked WPT per session (min) } \\
\hline Mean $( \pm S D)$ & $33.1( \pm 9.35)$ & & \\
\hline $\begin{array}{l}\text { Median (5-95 } \\
\text { percentile) }\end{array}$ & $30.0(25-54)$ & & \\
\hline (Minimum-maximum) & $(21-64)$ & & \\
\hline \multicolumn{4}{|c|}{ Location of WPT smoking in homes } \\
\hline Indoors n $(\%)$ & $28(56)$ & & \\
\hline Outdoors** $n(\%)$ & $22(44)$ & & \\
\hline \multicolumn{4}{|c|}{$\begin{array}{l}\text { * Research Assistants weighted } 10 \mathrm{~g} \text { WPT using an analytical balance and loaded it } \\
\text { in the WP head. } \\
\text { tSmoked WPT residue=WPT remaining at end of a smoking session. } \\
\text { fResearch Assistants measured } 470 \mathrm{~mL} \text { of water and placed it in the WP bowl. } \\
\text { §Smoked WP water = Water remaining in WP bowl at end of a smoking session. } \\
\text { IIIndoors = Participants smoked in the living room, kitchen, or bedroom. } \\
\text { ** Outdoors = Participants smoked in the backyard, on the patio, or balcony. } \\
\text { n, number of participants; WP, waterpipe; WPT, waterpipe tobacco. }\end{array}$} \\
\hline
\end{tabular}

$470 \mathrm{~mL}$ water in the WP bowl (table 2). Of the $10 \mathrm{~g}$ WPT, smokers consumed an average of $2.99 \mathrm{~g} \mathrm{WPT} / \mathrm{smoking}$ session, discarding the remainder (mean=7.01 g) as waste (smoked WPT residue) (table 2). Of the initial $470 \mathrm{~mL}$ of fresh WP water, an average of $443 \mathrm{~mL}$ (94\%) was discarded postsmoking as waste (smoked WP water) (table 2, figure 1).

\section{Disposal of postsmoking WPT and charcoal waste}

The majority of respondents reported discarding the smoked WPT residue in the trash (81.6\%) or the kitchen sink (14.3\%);

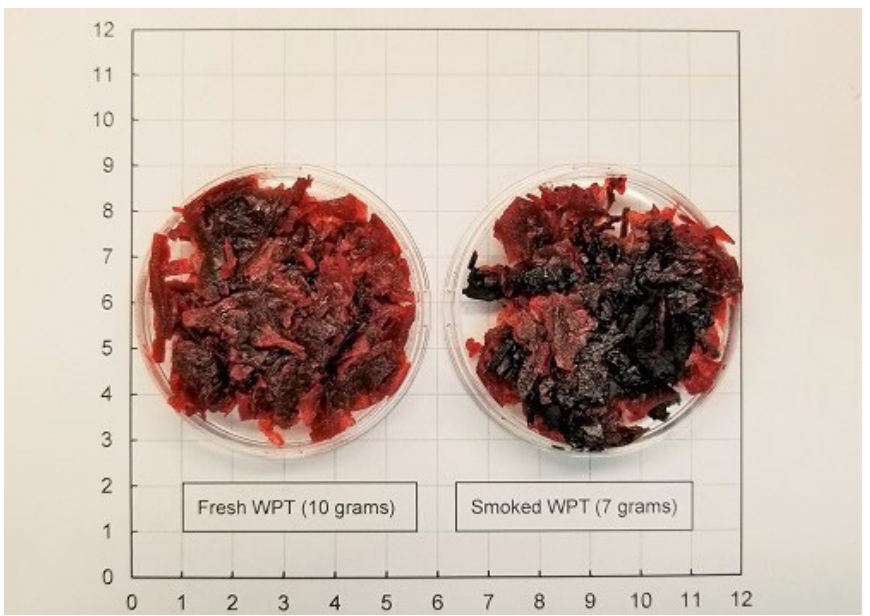

Figure 1 Fresh WPT and smoked WPT (scale: $1 \mathrm{~cm}$ ). WPT, waterpipe tobacco. other locations included backyard soil and indoor plant pots (table 1). About half of respondents reported discarding the burnt charcoal in the trash $(55.1 \%)$ or the kitchen sink (28.6\%); other locations included backyard soil, toilet and indoor plant pots (table 1).

\section{Disposal and characteristics of smoked WP water}

Respondents reported replacing the smoked WP water with fresh water after smoking an average of two WPT heads. The majority of respondents discarded the smoked WP water in the kitchen sink (72\%) or the bathroom sink (13.7\%); other locations included backyard soil, toilet and street storm drain (table 1).

When discarding the smoked WP water, about half of the respondents $(52.2 \%)$ reported an odour (eg, burnt tobacco scent or the flavour of the WPT), and $42.6 \%$ usually saw a residue (eg, tobacco or particles/flakes/ashes). The colour of smoked WP water after smoking one WPT head at home ranged from 'black' to 'clear' or the colour of the WPT used (table 3).

\section{WP hose cleaning practices}

Participants reported using the same WP hose for about 6 months (table 1). About one-third (31.3\%) never cleaned it (table 1). For those who reported ever cleaning their WP hose, most $(64.5 \%)$ did not clean it after every smoking session (table 1). Instead, cleaning frequency ranged from 'twice weekly' to 'once' or was dependent on frequency of use (eg, 'every other time' or 'every five to six uses') (table 4). Participants most often used water only or water and soap to clean the WP hose (table 4). The majority of respondents reported cleaning the WP hose in the kitchen sink (78.8\%); other locations included the bathroom sink and backyard (table 1).

\section{WP stem cleaning practices}

Participants reported using the same WP stem for about 6 months (table 1). About a quarter (27.7\%) never cleaned it (table 1). For those who reported ever cleaning their WP stem, $50 \%$ did not clean it after every smoking session (table 1). Instead, cleaning frequency ranged from 'weekly' to 'rarely' or depended on frequency of use (eg, 'every other time' or 'every five to six uses') (table 4). Water only or soap and water were most often used to clean the WP stem. The majority of respondents cleaned their WP stem in the kitchen sink (85.6\%); other locations included the bathroom sink, shower and backyard (table 1).

\section{DISCUSSION}

This is the first study to quantify two constituents of postsmoking WPT waste in home settings: smoked WPT residue and smoked WP water. We found that two-thirds (70.1\%) of WPT used by one smoker in a smoking session and almost all (94.3\%) water used in the WP bowl were discarded as waste. This is also the first study to identify locations of disposal of postsmoking WPT waste associated with using and cleaning WP devices in home settings. We found that WPT smokers who smoke at home usually discard postsmoking WPT waste in both indoor and outdoor environments, including the trash, kitchen sink, bathroom sink, toilet, shower, indoor plant pots, backyard soil and street storm drains.

Indoors, the kitchen may be most affected by disposal of WPT waste. In the USA, trash bins are typically placed in the kitchen area, where smokers reported discarding their WPT 
Table 3 Reported description of colour, odour and materials in water in WP bowl after one use (smoked WP water)

\begin{tabular}{|c|c|c|}
\hline & $\mathrm{n}(\%)$ & Quotes \\
\hline Colour of smoked WP water & & After smoking 1 WPT head at home, what is usually the colour of the water in the WP bowl? ( $n=58)$ \\
\hline Brown & $16(27.5)$ & Brown (8). Light brown (2). Tan (1). Colour of tobacco (1). Dirty brown (1). Brown-like soil pieces (1). Just brown liquid (1). Dark brown (1). \\
\hline White/grey/black & $11(19)$ & Somewhat clear (1). It is smoky clear (1). White (2). Foggy grey (4). Mostly cloudy (1). It looks a silver colour (1). Black/dark (1). \\
\hline Yellow & $11(19)$ & Light yellow (5). Yellow (4). Dark yellow (1). Amber (1). \\
\hline Clear & $9(15.5)$ & Clear (7). Pretty clear (1). Pretty clear depending on how long I was smoking (1). \\
\hline Pink/Red & $7(12.1)$ & Pink (1). Pinkish clear (1). Reddish colour (2). Orange (3). \\
\hline Tobacco flavour colour & $4(6.9)$ & Colour of flavour (1). It is usually the colour of the syrup from the tobacco (1). Colour of tobacco (2). \\
\hline Odour of smoked WP water & & After smoking 1 WPT head at home, when you pour the water out of the WP bowl, do you usually smell anything? If Yes, describe the odour: ( $n=22$ ) \\
\hline Tobacco/Cigarette/Smoke & $10(45.5)$ & $\begin{array}{l}\text { Somewhat the flavour of the tobacco (3). Burnt tobacco (1). Tobacco smell (2). Smells like charcoal and burned tobacco (1). Cigarettes in water (1). Smells like stale smoke } \\
\text { (1). Smoke and flavour (1). }\end{array}$ \\
\hline Tar/Burnt/Ash & $7(31.8)$ & Just tary and burnt (1). Tar-like smell (1). A lot burn with the smell of hookah (1). Burnt sheesh (2). Ashy (2). \\
\hline Dirty/Harsh & $5(22.7)$ & Dirty water smell (1). Stinking hookah water (1). Stale charcoal water (1). Dirty hookah water (1). Harsh (1). \\
\hline Materials in the WP bowl & & After discarding the water from the WP bowl, do you usually see any material left in the WP bowl? If Yes, describe the material: $(n=23)$ \\
\hline Tobacco & $13(56.5)$ & $\begin{array}{l}\text { Tobacco residue (1). Small tobacco flakes (1). Leaves (1). Tobacco specks (1). Some pieces of tobacco (1). Sometimes tobacco (1). Tobacco (1). Tobacco leaves (1). Hits of } \\
\text { sheesha (1). Burnt sheesh (3). Dark pieces like tar or residue of sheesha (1). }\end{array}$ \\
\hline Particles/Flakes/Ash & $7(30.4)$ & Little particles (1). It's clear particles (1). Small black particles (1). Particulates (1). Black/dark flakes (1). Ash (1). Murky with random pieces in it (1). \\
\hline Buildup/Residue/Juice & $3(13.1)$ & Some buildup on the sides of jar (1). Residue (1). Juice (1). \\
\hline
\end{tabular}

WP, waterpipe; WPT, waterpipe tobacco.

waste and usually remain in the home environment for about a week before being collected by waste management; therefore, there may be continuous lingering emission of postsmoking WPT toxic chemicals in indoor air (ie, thirdhand smoke (THS)), ${ }^{44-51}$ which may be inhaled by smokers and nonsmokers residing in the home.

THS (also known as residual or aged tobacco smoke) is an environmental health hazard consisting of tobacco smoke particles and toxicants that accumulate and remain over long periods of time in the smoker indoor home environments. ${ }^{44-48}$ Furthermore, THS constituents react with surrounding chemicals in the air forming secondary toxicants such as the potent carcinogenic tobacco-specific nitrosamines. ${ }^{48} 49$ THS causes DNA damage in human cells, ${ }^{50}$ and in animal studies it stimulated risk factors for inflammation-induced diseases, for example, chronic obstructive lung disease and asthma. ${ }^{51} \mathrm{We}$ have previously found nicotine in the air and on household surfaces in the living rooms and children's bedrooms in homes of WPT smokers. ${ }^{38}$ THS studies are focused on cigarettes; however, more studies are needed to characterise and quantify THS levels in homes of WPT smokers to inform interventions to reduce THS exposure from smoking and from discarding of related waste indoors.

Outdoors, the backyard soil may be most affected by smoked WPT residue, burnt charcoal and smoked WP water. This waste may adversely affect children playing outdoors, as well as pets and vegetation. Postsmoking WPT waste discarded in indoor or outdoor home environments will end up in landfills and water resources, ${ }^{1493233}$ harming the environment.

To reduce the accumulation of postsmoking WPT waste in the environment (eg, smoked WPT residue, aluminium foil and packaging), we suggest tailoring and adopting waste management options based on recommendations and polices enacted for recycling cigarette butts and remnants of smoked cigarette tobacco. The Extended Producer Responsibility (EPR) and Product Stewardship (PS) principles could guide controlling postsmoking WPT waste. ${ }^{2-5} 52$ EPR and PS principles, currently enacted in the USA and other countries on products, such as paint and batteries, ${ }^{2-5}$ can be applied to extend the responsibility and cost of managing postsmoking WPT waste to manufacturers, vendors, WPT smoking commercial venues (eg, hookah lounges/cafes) and consumers.
Approaches could include a WPT waste management tax embedded in the retail price of WPT, a mandatory deposit on WPT packages to provide an incentive to recycle and a disincentive to discard them in indoor and outdoor environments and a recycling programme, such as those that currently exist for cigarette waste. ${ }^{52-57}$ Since postsmoking WPT waste has international implications, health departments, particularly in countries with high WPT prevalence rates, could support the development of recycling programme with upcycling capabilities similar to TerraCycle (active in 25 countries), which does not landfill or incinerate tobacco waste, instead turning it into fertiliser, fuel and energy products for transportation and electricity. $^{5556}$

To be effective, these strategies would require a recycling infrastructure as well as consumer awareness campaigns. Simple first steps could include requiring manufacturers to print recycling symbols-which they currently lack-on WPT packages; and requiring owners of WPT retail stores, online point of sale stores and hookah lounges/cafes to display recycling symbols. However, WPT packages may be contaminated with WPT toxic chemicals inappropriate for disposal in drains and landfills and best handled by a recycler of both tobacco waste and packages.

These strategies do not address the safe disposal of smoked WP water or burnt charcoal, which contain toxic chemicals, and cannot be recycled or recollected once discarded in the environment. ${ }^{33}$ For WPT, reducing WPT products' ingredients classified by the US Food and Drug Administration (a federal agency authorised by the 2009 Family Smoking Prevention and Control Act to regulate tobacco products including WPT) ${ }^{58-60}$ as harmful and potentially harmful constituents may minimise some of the toxins in WPT waste and thus reduce their adverse environmental impact. For charcoal, strategies to replace it with heating devices to heat the WPT during smoking may reduce charcoal waste.

Proper cleaning practices may reduce some harm to WPT smokers. Most of WPT smokers share their WP with friends and family and at times with strangers, ${ }^{61}$ and we found that some smokers never cleaned their WP device. Sharing a WP between smokers is associated with transmission of infectious diseases via saliva and fecal-oral routes. ${ }^{62-65}$ Research is needed to identify levels of WP device contamination in home 


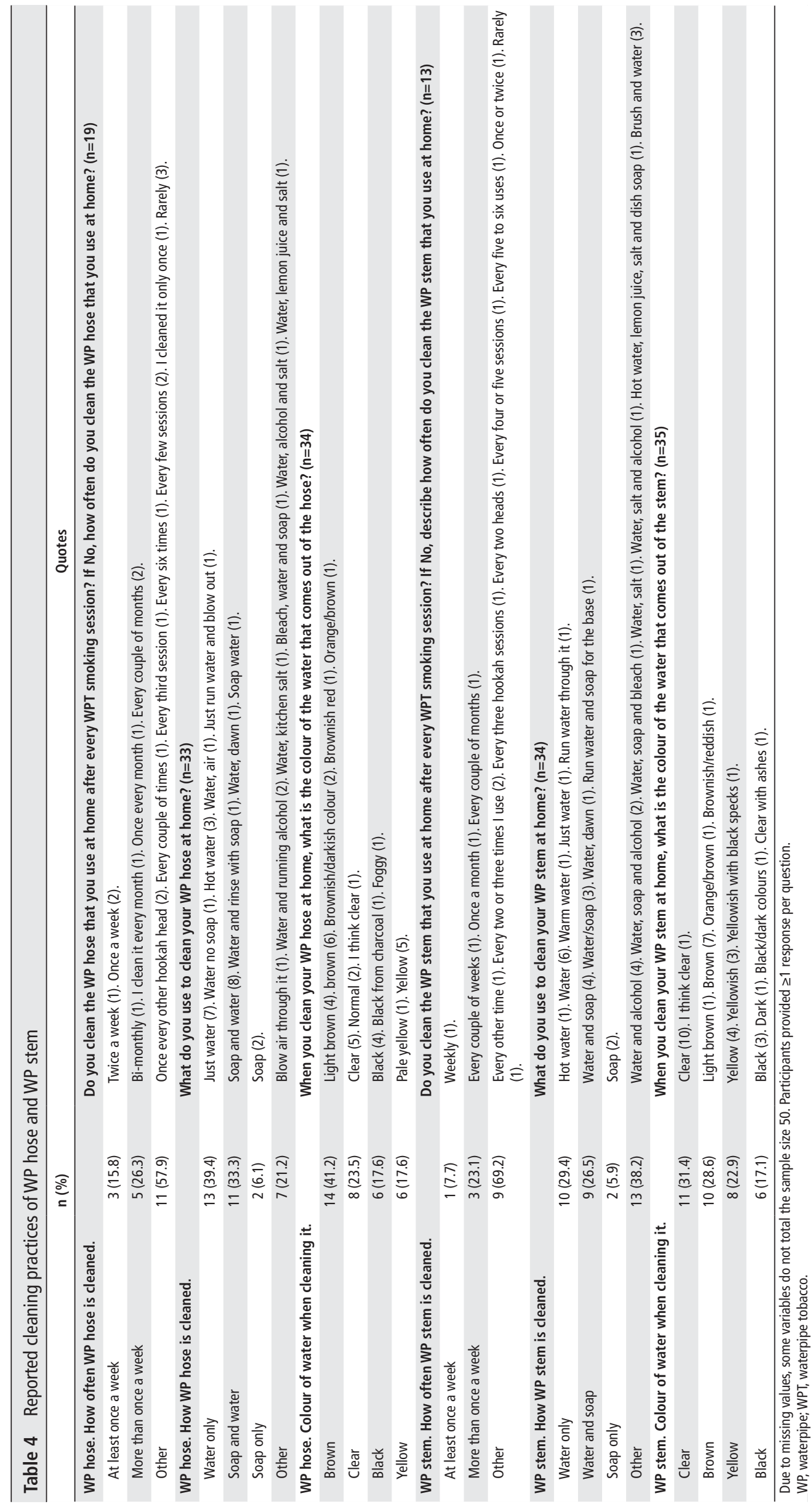


settings, recommend and encourage proper cleaning practices of WP devices in homes and investigate cleaning practices in public WPT venues.

Furthermore, as described by the participants, the dark/ brownish/yellowish colour of smoked WP water and WP hose/stem cleaning water, the tobacco/tar/dirty odour and the deposited materials/flakes of tobacco in smoked WP water suggest a potential buildup of toxic chemicals, particularly in WP devices that are rarely cleaned. Studies are needed to characterise and quantify components of the buildup of toxic chemicals in hookah devices (eg, tobacco, humectants and flavouring additivities) to determine their corresponding health risks; meanwhile tobacco control interventions should develop optimal cleaning strategies for WP devices and communicate findings to the WPT consumer via awareness campaigns.

\section{Limitations}

Our findings and recommendations were based on smoking sessions in which participants in our small San Diego US sample, ages 21-35 years, smoked alone in their own home. However, the majority $(88 \%)$ of participants reported that they almost always smoked with someone else. Therefore, data on smoked WPT residue amount and smoked WP water quality could be underestimated. Future research should collect data from group smoking sessions, sample different populations including older adults with various sociodemographic backgrounds and extend our investigation to commercial WPT smoking venues in the USA and other countries.

While we did ask WPT smokers about cleaning practices of the WP hose and WP stem, we did not ask about the WP bowl; future research should include cleaning practices of the WP bowl, as toxic chemicals may accumulate on its surfaces. We did not ask participants about the disposal location of the empty packages of WPT or the aluminium foil used to cover the WPT during smoking; our recommendations for recycling postsmoking WPT waste are applicable to these components.

Missing responses in some of our open-ended questions is a concern that the data might not represent the population well, given our sample size of 50 .

\section{What this paper adds}

What is already known on this subject

- Environmental waste is generated from waterpipe tobacco (WPT) smoking.

- Waterpipe (WP) users smoke in home settings.

- Studies have examined neither postsmoking WP device cleaning practices nor the disposal of waste associated with smoking WPT in home settings.

\section{What this paper adds}

- About two-thirds of the original weight of WPT smoked in a home setting was discarded as waste.

- Not all WPT smokers clean their WP device components after each use in a home setting.

- Locations where WPT smokers reported discarding waste associated with using and cleaning their WP device in home settings included the trash, kitchen sink, bathroom sink, toilet, indoor plant pots, backyard soil and street storm drains.

\section{CONCLUSIONS}

The increasing prevalence of WPT smoking globally warrants including postsmoking WPT waste in programme aimed to control disposal of overall tobacco waste. The WHO and American Cancer Society have provided data on annual cigarette production and volume of associated waste discarded in the environment. ${ }^{9}{ }^{10}$ Such organisations and individual countries, particularly those with high WPT smoking prevalence, are encouraged to lead similar efforts to estimate global volume of WPT production and associated waste. These data are needed to justify efforts to tailor programme and policies at the city, state, national and international levels to mitigate the adverse environmental impact of WPT waste.

Acknowledgements We thank our participants, our research assistants (Shadeh A. Rassoulkhani, Mayra Z. Duran, CyrielleJeanne Pagharion, Krystle Liz E. Diaz, Rahwa G. Weldeselase, Tamara Vu, Warda Haq), and our CBEACH support staff (Jennifer A. Jones and Benjamin Nguyen).

Contributors Conception, design and development of methodology: NOFK and NOK. Recruitment, acquisition of data, study supervision and administrative, technical or material support: NOFK, NOK, SL, ER, FK-P and AIBP. Data analysis and interpretation of data: NOFK, SL, ER, NOK and MFH. All authors contributed to manuscript preparation and approved the final version prior to submission.

Funding Research reported in this publication was supported by the US Food and Drug Administration (FDA) Center for Tobacco Products and the National Institute on Drug Abuse of the National Institutes of Health (NIH) under Award Number R01DA042471 to Nada OF Kassem.

Disclaimer The content is solely the responsibiliy of the authors and does not necessarily represent the official views of the Food and Drug Administration or the National Institutes of Health.

Competing interests None declared.

Patient consent for publication Not required.

Ethics approval The study was approved by San Diego State University's Institutional Review Board (IRB\# 2445100).

Provenance and peer review Not commissioned; externally peer reviewed.

Data sharing statement All data relevant to the study are included in the article or uploaded as supplementary information.

\section{ORCID iDs}

Nada OF Kassem http://orcid.org/0000-0002-5403-7234

Sandy Liles http://orcid.org/0000-0003-3240-7799

\section{REFERENCES}

1 Wallbank LA, MacKenzie R, Beggs PJ. Environmental Impacts of tobacco product waste: international and Australian policy responses. Ambio 2017;46:361-70.

2 Curtis C, Novotny TE, Lee K, et al. Tobacco industry responsibility for butts: a model tobacco waste act. Tob Control 2017;26:113-7.

3 Novotny TE, Slaughter E. Tobacco product waste: an environmental approach to reduce tobacco consumption. Curr Environ Health Rep 2014;1:208-16.

4 Novotny TE, Lum K, Smith E, et al. Cigarettes butts and the case for an environmental policy on hazardous cigarette waste. Int J Environ Res Public Health 2009;6:1691-705.

5 Barnes RL. Regulating the disposal of cigarette butts as toxic hazardous waste. Tob Control 2011;20 Suppl 1:i45-8.

6 Slaughter E, Gersberg RM, Watanabe K, et al. Toxicity of cigarette butts, and their chemical components, to marine and freshwater fish. Tob Control 2011;20 Suppl 1:i25-9.

7 Smith EA, Novotny TE. Whose butt is it? tobacco industry research about smokers and cigarette butt waste. Tob Control 2011;20 Suppl 1:i2-9.

8 Schneider JE, Peterson NA, Kiss N, et al. Tobacco litter costs and public policy: a framework and methodology for considering the use of fees to offset abatement costs. Tob Control 2011;20 Suppl 1:i36-41.

9 World Health Organization. Tobacco and its environmental impact: an overview. Geneva: 2017. License: CC BY-NC-SA 3.0 IGO. Available: http://apps.who.int/ iris/bitstream/handle/10665/255574/9789241512497-eng.pdf?sequence=1\& isAllowed =y [Accessed Dec 2018].

10 Eriksen M, Mackay J, Schluger N, et al. The tobacco atlas [Online]. American Cancer Society, Inc.: Atlanta, GA, 2015. Available: http://3pk43×313ggr4cy0lh3tctih. wpengine.netdna-cdn.com/wp-content/uploads/2015/03/TA5_2015_WEB.pdf [Accessed Dec 2018]. 
11 Maziak W, Taleb ZB, Bahelah R, et al. The global epidemiology of waterpipe smoking. Tob Control 2015;24 Suppl 1:i3-12.

12 Jawad M, Charide R, Waziry R, et al. The prevalence and trends of waterpipe tobacco smoking: a systematic review. PLoS One 2018;13:e0192191.

13 Morton J, Song Y, Fouad H, et al. Cross-country comparison of waterpipe use: nationally representative data from 13 low and middle-income countries from the global adult tobacco Survey (GATS). Tob Control 2014;23:419-27.

14 Agaku IT, Filippidis FT, Vardavas $\mathrm{Cl}$, et al. Poly-tobacco use among adults in 44 countries during 2008-2012: evidence for an integrative and comprehensive approach in tobacco control. Drug Alcohol Depend 2014;139:60-70.

15 Jawad M, Lee JT, Millett C. Waterpipe tobacco smoking prevalence and correlates in 25 Eastern Mediterranean and Eastern European countries: cross-sectional analysis of the global youth tobacco survey. NICTOB 2016;18:395-402.

16 Singh T, Arrazola RA, Corey CG, et al. Tobacco Use Among Middle and High School Students--United States, 2011-2015. MMWR Morb Mortal Wkly Rep 2016;65:361-7.

17 Grekin ER, Ayna D. Waterpipe smoking among college students in the United States: a review of the literature. J Am Coll Health 2012;60:244-9.

18 Johnson AL, Collins LK, Villanti AC, et al. Patterns of nicotine and tobacco product use in youth and young adults in the United States, 2011-2015. Nicotine Tob Res 2018;20(suppl_1):S48-S54.

19 Odani S, Armour BS, Graffunder CM, et al. State-Specific Prevalence of Tobacco Product Use Among Adults - United States, 2014-2015. MMWR Morb Mortal Wkly Rep 2018;67:97-102.

20 Kasza KA, Ambrose BK, Conway KP, et al. Tobacco-Product use by adults and youths in the United States in 2013 and 2014. N Engl J Med 2017;376:342-53.

21 Kassem NOF, Jackson SR, Boman-Davis M, et al. Hookah smoking and facilitators/ barriers to lounge use among students at a US university. Am J Health Behav 2015:39:832-48.

22 Kassem NOF, Kassem NO, Jackson SR, et al. Arab-American hookah smokers: initiation, and pros and cons of hookah use. Am J Health Behav 2015;39:680-97.

23 Khater AEM, Abd El-Aziz NS, Al-Sewaidan HA, et al. Radiological hazards of narghile (hookah, shisha, goza) smoking: activity concentrations and dose assessment. J Environ Radioact 2008;99:1808-14

24 Schubert J, Luch A, Schulz TG. Waterpipe smoking: analysis of the aroma profile of flavored waterpipe tobaccos. Talanta 2013;115:665-74.

25 Schubert J, Heinke V, Bewersdorff J, et al. Waterpipe smoking: the role of humectants in the release of toxic carbonyls. Arch Toxicol 2012;86:1309-16.

26 Sepetdjian E, Abdul Halim R, Salman R, et al. Phenolic compounds in particles of mainstream waterpipe smoke. Nicotine Tob Res 2013:15:1107-12.

27 Kassem NOF, Kassem NO, Liles S, et al. Acrolein exposure in hookah smokers and nonsmokers exposed to hookah tobacco secondhand smoke: implications for regulating hookah tobacco products. Nicotine Tob Res 2018;20:492-501.

28 AkI EA, Ward KD, Bteddini D, et al. The allure of the waterpipe: a narrative review of factors affecting the epidemic rise in waterpipe smoking among young persons globally. Tob Control 2015;24(Suppl 1):i13-21.

29 El-Zaatari ZM, Chami HA, Zaatari GS. Health effects associated with waterpipe smoking. Tob Control 2015;24(Suppl 1):i31-43.

30 Waziry $\mathrm{R}$, Jawad M, Ballout RA, et al. The effects of waterpipe tobacco smoking on health outcomes: an updated systematic review and meta-analysis. Int J Epidemiol 2017:46:32-43.

31 Rezk-Hanna M, Benowitz NL. Cardiovascular effects of hookah smoking: potential implications for cardiovascular risk. Nicotine Tob Res 2018:1-11.

32 Al-Kazwini AT, Said AJ, Sdepanian S. Compartmental analysis of metals in waterpipe smoking technique. BMC Public Health 2015;15.

33 Qamar W, Al-Ghadeer AR, Ali R. Analysis of toxic elements in smoked shisha waterwaste and unburnt tobacco by inductively coupled plasma-mass spectrometry: probable role in environmental contamination. Research Journal of Environmental Toxicology 2015;9:204-10

34 Schubert J, Bewersdorff J, Luch A, et al. Waterpipe smoke: a considerable source of human exposure against furanic compounds. Analytica Chimica Acta 2012;709:105-12.

35 Schubert J, Kappenstein O, Luch A, et al. Analysis of primary aromatic amines in the mainstream waterpipe smoke using liquid chromatography-electrospray ionization tandem mass spectrometry. Journal of Chromatography A 2011;1218:5628-37.

36 Bagheri H, Zeinali S, Baktash MY. A single-step synthesized supehydrophobic melamine formaldehyde foam for trace determination of volatile organic pollutants. Journal of Chromatography A 2017;1525:10-16

37 Peterson LA, Cummings ME, Chan JY, et al. Identification of a cis -2-Butene-1,4-dialderived Glutathione Conjugate in the Urine of Furan-Treated Rats. Chem. Res. Toxicol. 2006;19:1138-41.

38 Kassem NOF, Daffa RM, Liles S, et al. Children's Exposure to Secondhand and Thirdhand Smoke Carcinogens and Toxicants in Homes of Hookah Smokers. Nicotine Tob Res 2014:16:961-75.

39 Kassem NOF, Kassem NO, Liles S, et al. Levels of urine cotinine from hookah smoking and exposure to hookah tobacco secondhand smoke in hookah lounges and homes. Int J High Risk Behav Addict 2018;7:e67601.
40 Agaku I, Odani S, Armour B, et al. Social aspects of hookah smoking among US youth Pediatrics 2018;142.

41 Heinz AJ, Giedgowd GE, Crane NA, et al. A comprehensive examination of hookah smoking in college students: use patterns and contexts, social norms and attitudes, harm perception, psychological correlates and co-occurring substance use. Addictive Behaviors 2013;38:2751-60.

42 Lipkus IM, Eissenberg T, Schwartz-Bloom RD, et al. Affecting perceptions of harm and addiction among college waterpipe tobacco smokers. Nicotine \& Tobacco Research 2011;13:599-610

43 Maziak W, Ward KD, Eissenberg T. Factors related to frequency of narghile (waterpipe) use: the First insights on tobacco dependence in narghile users. Drug and Alcohol Dependence 2004;76:101-6.

44 Díez-Izquierdo A, Cassanello-Peñarroya P, Lidón-Moyano C, et al. Update on thirdhand smoke: a comprehensive systematic review. Environmental Research 2018;167:341-71

45 Jacob P, Benowitz NL, Destaillats $H$, et al. Thirdhand smoke: new evidence, challenges, and future directions. Chem. Res. Toxicol. 2017:30:270-94.

46 Matt GE, Quintana PJE, Destaillats H, et al. Thirdhand tobacco smoke: Emerging evidence and arguments for a multidisciplinary research agenda. Environmental Health Perspectives 2011;119:1218-26.

47 Matt GE, Quintana PJE, Zakarian JM, et al. When smokers move out and non-smokers move in: residential thirdhand smoke pollution and exposure. Tobacco Control 2011;20:e1.

48 Ramírez N, Özel MZ, Lewis AC, et al. Exposure to nitrosamines in thirdhand tobacco smoke increases cancer risk in non-smokers. Environment International 2014;71:139-47.

49 Sleiman M, Gundel LA, Pankow JF, et al. Formation of carcinogens indoors by surface-mediated reactions of nicotine with nitrous acid, leading to potential thirdhand smoke hazards. Proceedings of the National Academy of Sciences 2010;107:6576-81.

50 Hang B, Sarker AH, Havel C, et al. Thirdhand smoke causes DNA damage in human cells. Mutagenesis 2013;28:381-91.

51 Adhami N, Chen Y, Martins-Green M. Biomarkers of disease can be detected in mice as early as 4 weeks after initiation of exposure to third-hand smoke levels equivalent to those found in homes of smokers. Clin. Sci. 2017:131:2409-26.

52 Curtis C, Collins S, Cunningham S, et al. Extended producer responsibility and product stewardship for tobacco product waste. Int J Waste Resour 2014:4.

53 World Health Organization. Guidelines for implementation of article 5.3 of the WHO Framework Convention on Tobacco Control on the protection of public health policies with respect to tobacco control from commercial and other vested interests of the tobacco industry. Technical report. Geneva, 2008. Available: https://www.who.int/fctc guidelines/article_5_3.pdf [Accessed Dec 2018].

54 RecycleNation. How to recycle cigarette ashes and waste, 2015. Available: https:// recyclenation.com/2015/05/how-to-recycle-cigarette-ashes-and-waste/ [Accessed Dec 2018]

55 City of Vancouver. Cigarette butt recycling project, 2018. Available: https://vancouver. ca/green-vancouver/on-the-street.aspx [Accessed Dec 2018].

56 TerraCycle. TerraCycle's global impact, 2018. Available: https://www.terracycle.com/ en-US/ [Accessed Dec 2018]

57 Container Recycling Institute. Bottle bill resource guide, 2018. Available: http://www. bottlebill.org/ [Accessed Dec 2018].

58 Food and Drug Administration, HHS. Deeming Tobacco Products To Be Subject to the Federal Food, Drug, and Cosmetic Act, as Amended by the Family Smoking Prevention and Tobacco Control Act; Restrictions on the Sale and Distribution of Tobacco Products and Required Warning Statements for Tobacco Products. Final rule. Fed Regist 2016;81:28973-9106 https://www.govinfo.gov/content/pkg/FR-2016-05-10/ pdf/2016-10685.pdf

59 McCarthy M. FDA moves to regulate E-cigarettes and pipe and hookah tobacco. BMJ 2014:348:g2952.

60 US Food and Drug Administration. Tobacco products. Youth \& Tobacco, 2019 Available: https://www.fda.gov/tobaccoproducts/publichealtheducation/protectingk dsfromtobacco/default.htm [Accessed March, 2019]

61 Kassem NOF, Jackson SR, Kassem NO, et al. College student beliefs and behavior regarding sharing when smoking hookahs. am j health behav 2019;43:133-44.

62 Martinasek M, Rivera Z, Ferrer A, et al. A pilot study to assess the bacterial contaminants in hookah pipes in a community setting. int $j$ tuberc lung dis 2018;22:579-84.

63 Alaidarous M, Alanazi M, Abdel-Hadi A, Isolation A-HA. Isolation, identification, and antimicrobial susceptibility of bacteria associated with waterpipe contaminants in selected area of Saudi Arabia. BioMed Research International 2017;2017:1-7

64 Masadeh M, Hussein E, Alzoubi K, et al. Identification, characterization and antibiotic resistance of bacterial isolates obtained from waterpipe device hoses. IJERPH 2015;12:5108-15.

65 Safizadeh H, Moradi M, Rad MR, et al. Bacterial contamination of different components of the waterpipe. int $j$ tuberc lung dis 2014;18:988-91. 